\title{
Formação conceitual em crianças participantes do Orçamento Participativo de Fortaleza
}

Conceptual development on participants children of Fortaleza's Participatory Budget

La formación de conceptos en los niños que participan en el Presupuesto Participativo de Fortaleza

\section{Leonardo Barros Soares}

Universidade Federal de Minas Gerais, Belo Horizonte, MG, Brasil.

\section{Resumo}

O Estatuto da Criança e do Adolescente (Lei 8.060/1990) estabelece o direito de crianças e adolescentes de participação na vida política da comunidade em que vivem. A política de Orçamento Participativo (OP) de Fortaleza visa concretizar este preceito legal ao realizar atividades específicas para esta população. Indagações, entretanto, acerca da capacidade cognitiva e moral deste segmento populacional de compreensão do complexo jogo das correlações de forças existentes no processo do OP e de participação efetiva nas decisões e discussões empreendidas em suas atividades fazem parte do cotidiano da política. Utilizando o arcabouço teórico-metodológico da psicologia histórico-cultural de L.S.Vigotsky e recorrendo à nossa experiência na elaboração e execução de atividades para crianças e adolescentes que participam do OP discorremos sobre possíveis implicações psicopedagógicas de crianças e adolescentes na política orçamentária municipal enfocando, de forma específica, o processo de formação conceitual.

Palavras-chave: Participação, Crianças e Adolescentes, Psicopedagogia.

\section{Resumen}

El Estatuto del Niño y del Adolescente (Ley 8.060/1990) establece el derecho de los niños y adolescentes a participar en la vida política de la comunidad en que viven. La política de Presupuesto Participativo (PP) de Fortaleza, está dirigido a la aplicación de esta disposición legal para llevar a cabo actividades específicas para esta población. Preguntas, sin embargo, sobre el desarrollo cognitivo y moral de este segmento de la población a entender la compleja interacción de las correlaciones de poder en el PP y la participación efectiva en las decisiones y los debates realizados en sus actividades son parte de la política cotidiana. Utilizando el 
marco teórico y metodológico de la psicología histórico-cultural de L.S.Vigotsky y el uso de nuestra experiencia en el diseño y ejecución de actividades para niños y adolescentes que participan en el PP sobre las posibles implicaciones psicopedagógicas de los niños y adolescentes en el proceso de formación de conceptos.

Palabras clave: Participación, Niños y Adolescentes, Psicología.

\begin{abstract}
The Statute of Children and Adolescents (Law 8.060/1990) establishes the right of children and adolescents to participate in the political life of the community in which they live. The Participatory Budget (PB) of Fortaleza is aimed at implementing this legal provision to carry out activities specific to this population..Inquiries about the cognitive and moral understanding of this population segment of the complex interplay of power correlations in the $\mathrm{PB}$ process and effective participation in decisions and discussions undertaken in its activities are part of daily politics. Using the theoretical and methodological framework of cultural-historical psychology from LS Vigotsky and using our experience in developing and implementing activities for children and adolescents who participate in the PB we took on possible psychological implications for children and adolescents of the participation in the municipal PB policy, focusing on the process of concept formation.
\end{abstract}

Keywords: Participation, Childrens and Adolescents, Psychopedagogy.

\title{
Introdução
}

A experiência do Orçamento Participativo (OP) de Fortaleza foi reconhecida internacionalmente em 2007 por seu trabalho com as populações historicamente discriminadas no processo de tomada de decisões - negros, mulheres, pessoas com deficiência, idosos, jovens, a população LGBTT (Lésbicas, Gays, Bissexuais, Travestis e Transgêneros) e crianças e adolescentes - recebendo o prêmio "Boa Prática em Participação Cidadã", conferido pelo Observatório
Internacional de Democracia Participativa (OIDP). Em 2009, o conjunto de suas metodologias e experiências com o Orçamento Participativo Criança e Adolescente (OPCA) foi certificado com o título de "tecnologia social" pela Fundação Banco do Brasil, o que indica sua qualidade e efetividade na promoção da participação de crianças e adolescentes na política em questão. $\mathrm{O}$ direito, a legitimidade e as implicações desta participação, entretanto, não são 
consensuais nem entre os membros da equipe executora da política, nem entre seus gestores e muito menos entre a população participante. Indagações acerca da capacidade cognitiva e moral de crianças e adolescentes de compreensão do complexo jogo das correlações de forças existentes no processo do OP e de participação efetiva e responsável nas decisões e discussões empreendidas em suas atividades fazem parte do cotidiano da política e se anunciam como desafios que solicitam uma maior atenção e aprofundamento por parte de todos aqueles implicados em sua gestão, execução e participação. Estes questionamentos a que aludimos desembocam, usualmente, em respostas evasivas ou conclusões taxativas, no mais das vezes amparadas em visões do senso comum, claramente preconceituosas e estereotipadas, que pouco contribuem para a compreensão real das implicações éticas, cognitivas e psicológicas da participação de crianças e adolescentes nas atividades do OP de Fortaleza.

Tendo em vista tal estado de coisas, será no intuito de fornecer subsídios para a construção de uma argumentação que encontre um sólido respaldo teórico para sua sustentação que colocaremos a questão de forma clara, e buscaremos, nas fontes necessárias, possíveis pistas para sua elucidação: a participação de crianças e adolescentes, a partir de seis anos de idade $^{1}$, na política de Orçamento Participativo, é justificável do ponto de vista cognitivo, psicológico e psicopedagógico? Quais são as implicações, no âmbito "psi”, desta participação?

No presente artigo pretendemos expor de forma resumida alguns pontos que compõem uma argumentação baseada na obra do psicólogo bielo-russo L.S.Vigotsky, no intuito de contribuir para este debate. Este trabalho, é preciso ressaltar, se apresenta como uma ainda incipiente e superficial incursão na obra vigotskyana, que carece de estudos experimentais - tão caros à escola de psicologia soviética - e baseia-se, sobretudo, em nossas experiências e observações como membro da equipe responsável pela realização de atividades formativas com a população participante da política pública de OP. Também é oportuno ressaltar que o mesmo é uma versão condensada de nosso trabalho de conclusão do curso de pós-graduação strictu sensu em Psicopedagogia Clínica, Hospitalar e Institucional, com caráter de ensaio eminentemente teórico situado no campo dos estudos do desenvolvimento infantil, que fornecerá algumas linhas gerais para uma possível investigação empírica a ser realizada no futuro com os sujeitos do processo. 
Em termos conceituais (Avritzer \& Navarro, 2003; Avritzer, 2007), o OP pode ser definido como uma experiência de política pública de promoção da participação popular na deliberação nos rumos decisórios do planejamento orçamentário de uma cidade ou estado, mais especificamente da Lei Orçamentária Anual $(\mathrm{LOA})^{2}$. Em Fortaleza esta política é executada desde 2005, contabilizando um montante de mais de 250 milhões de reais investidos em obras e serviços na cidade mediante a deliberação popular de cerca de mais de 128 mil pessoas ${ }^{3}$.

O Orçamento Participativo se organiza para atender a população da cidade de Fortaleza em dois níveis: a partir do "território" de origem do cidadão - no caso estudado, as subunidades administrativas da municipalidade, as Secretarias Executivas Regionais (SERs) ${ }^{4}$; e a partir do "segmento social"- juventude, idosos, pessoas com deficiência, mulheres, população negra, LGBTT e crianças e adolescentes - com o qual o indivíduo se identifica e afirma pertencer ${ }^{5}$.

As atividades que formam a política de OP se dão integradas num fluxo cíclico que, grosso modo, apresenta as seguintes etapas:

- Em termos territoriais primeiramente ocorrem, em diversos bairros e comunidades da cidade, as chamadas "reuniões comunitárias", oficinas pedagógicas ou grupos de discussão nos quais os diversos grupos sociais - associações de moradores, ONGs, entidades e demais grupos de pessoas encontram-se com a equipe executora da política para conhecer as áreas de atuação da Prefeitura, os limites orçamentários da Gestão e as peculiaridades de todas as fases que compõem o ciclo do OP.

- A segunda etapa do ciclo é aquela em que são realizadas, em 59 pontos que contemplam todas as SERs da cidade, as chamadas Assembléias Eletivas, grandes reuniões abertas em que a população participante lança e elege suas propostas de serviços e obras prioritárias a serem analisados pelos órgãos e secretarias competentes da gestão municipal. Os segmentos sociais, excetuando-se o de crianças e adolescentes, contam com uma Assembléia Eletiva de caráter municipal. Aquele segmento, por seu turno, participa de oito Assembléias Eletivas territoriais e de seis realizadas em escolas municipais que se disponibilizaram voluntariamente para participarem da política de OP.

- A terceira fase do processo é o de análise, por parte dos órgãos e secretarias da Prefeitura Municipal de Fortaleza, da viabilidade técnica, jurídica e financeira das demandas apresentadas pela população.

- A quarta fase é caracterizada pela realização de Assembléias Deliberativas 
em 59 pontos da cidade, em que os cidadãos e cidadãs poderão conhecer as propostas de realização de serviços e obras para aquela região e o orçamento disponível para tal, escolhendo aquelas que considerarem de maior importância. Também é nesta segunda assembléia que são eleitos os representantes da população que serão "delegados" do OP que, por sua vez, formam os Fóruns Regionais de Delegados em cada SER, responsáveis por debater e acompanhar o processo de execução das obras do OP em cada localidade. Os segmentos sociais, incluindo as crianças e adolescentes, também contam com suas Assembléias Deliberativas específicas e igualmente elegem seus próprios delegados.

- Por fim, estes delegados elegem entre si os membros do Conselho do Orçamento Participativo (COP), a instância máxima de deliberação da política, que congrega conselheiros do OP que representam a população das seis Secretarias Executivas Regionais da cidade.

É de interesse para este trabalho que nos debrucemos sobre os procedimentos metodológicos que adotamos nas atividades do OP com o recorte que nos interessa, a saber, aquelas destinadas especialmente para a população de crianças e adolescentes. Devemos sublinhar, de início, que as atividades realizadas com o segmento populacional da infância e da juventude são estruturadas de modo específico, apresentando um caráter mais lúdico do que aquelas realizadas com os adultos e demais segmentos.

Grosso modo, o foco de uma Assembléia Eletiva para este tipo de participante se dá basicamente através da distribuição, em pequenos grupos, da totalidade de crianças e adolescentes presentes. Uma vez nos grupos de discussão - que não devem ultrapassar o número de 20 participantes e são organizados de modo a aproximar faixas etárias - as crianças e adolescentes entram em contato com pelo menos dois membros da equipe executora da política, que devem conduzir as atividades com o grupo com o objetivo de que este possa elaborar propostas de realização de serviços e obras para sua comunidade ou para a cidade numa perspectiva ampliada.

Participando destas atividades na condição de elaboradores e executores da política de OP naquela cidade, pudemos acompanhar vis-à-vis o processo de participação de crianças e adolescentes na mesma. A peculiaridade de algumas das demandas apresentadas (6), a singularidade de percursos de raciocínio e de questionamento que nos fizeram durante as atividades, somadas aos questionamentos reiterados sobre a capacidade cognitiva de 
crianças e adolescentes de participarem ativamente das mesmas, nos levaram a nos perguntar sobre o processo de construção conceitual deste segmento populacional e, no limite, sobre a importância global, em termos psicopedagógicos, da participação destes em toda a política de OP.

Em nosso trabalho de conclusão de curso elaboramos, com o intuito de lançarmos luz de modo amplo às implicações psicopedagógicas em crianças e adolescentes decorrente de sua participação em atividades do OP, três ensaios que visavam responder às seguintes perguntas: primeiramente, é possível afirmar que crianças e adolescentes "constroem" conceitos? Em caso afirmativo, como este processo se desenrola? Ele também abrangeria a formação de conceitos políticos tais como a política de OP deseja fomentar?; Em segundo lugar, qual é a importância global em termos de desenvolvimento infantil da participação de crianças e adolescentes em atividades comunitárias, aí incluídas as atividades políticas?; Por fim, o que podemos discutir em termos psicopedagógicos quando compreendemos as atividades do OP como campos de mediação intergeracional em que crianças, adolescentes e adultos interagem democraticamente objetivando a consecução de determinados objetivos? No presente artigo, todavia, escolhemos reduzir o escopo de nossa investigação e nos aprofundar em nossa discussão relativa somente ao primeiro tópico destas indagações, por entendermos que o debate sobre a formação de conceitos e adolescentes condensa o ponto fulcral das dúvidas acerca da capacidade de participação de crianças e adolescentes no Orçamento Participativo de Fortaleza.

\section{O Orçamento Participativo de Fortaleza} e a formação de conceitos em crianças e adolescentes

Ramos (1984), numa crônica de sua autoria intitulada "Um novo A B C", nos conta como se deu seu aprendizado das primeiras letras, ainda no interior do estado das Alagoas. Na cartilha de alfabetização, apenas sílabas, frases soltas e máximas morais: "fala pouco e bem: ter-te-ão por alguém." Mas quem era esse Terteão e o que ele fazia ali no fim da frase? Ou ainda "a preguiça é a chave da pobreza." Morando no início do século XX numa das localidades inóspitas de um dos estados brasileiros mais pobres, Graciliano (1984, p.174) refletia:

\footnotetext{
"Que espécie de chave seria aquela? Aos seis anos, eu e meus companheiros de infelicidade escolar, quase todos pobres, não conhecíamos a pobreza pelo nome e tínhamos poucas chaves, de gavetas, de
} 
armários e de portas. Chave de pobreza para uma criança de seis anos é terrível."

A crítica bem humorada de Ramos (1984) ao método com o qual foi alfabetizado deixa entrever, além do conservadorismo reinante e da completa inadequação entre as experiências de vida dos educandos e as frases utilizadas no material didático, a dificuldade sentida pelo autor e seus "colegas de infortúnio" em "conhecer a pobreza pelo nome", ou, dito de outra forma, em abarcar o conceito de pobreza expresso na sentença.

Gostaríamos de estender a ponderação de Graciliano para pensarmos outros "nomes que não conhecemos pelo nome". Muitas das crianças e adolescentes que participam da política de Orçamento participativo de Fortaleza são pobres, mas será que "conhecem a pobreza pelo nome" ou apenas a vivenciam em seu dia-a-dia sem no entanto construir um conceito sobre sua situação sócio-econômica? Será que constroem um conceito sobre política ao assistirem ao programa eleitoral obrigatório na televisão em períodos eleitorais? Que tipo de conceito elaboram nas conversas com seus pais quando estes comentam sobre as negociações da prefeitura com a associação de moradores da qual fazem parte? Que tipo de conceito "político" engendram ao perceber que o modus operandi da quadrilha de traficantes do seu bairro é violento mas também, em alguns aspectos, aparentemente também é bastante eficaz?

No que tange à participação de crianças e adolescentes a partir de seis anos de idade nas atividades do Orçamento Participativo, a indagação que se desvela diante de nossa mirada teórica é a seguinte: estes indivíduos elaboram conceitos políticos, históricos e sociais de termos tais como "democracia", "controle social", "participação popular", "negociação", “diálogo", "política”, “orçamento”?

Estamos cônscios de que respostas conclusivas ao questionamento levantado são inviáveis haja vista a impossibilidade de realizarmos uma pesquisa de campo estruturada e de longo alcance com os sujeitos participantes da política. Não obstante, tentando lançar luz a possíveis argumentos que forneçam pistas valiosas para a tessitura de uma explicação para estas indagações, as investigações deste primeiro ensaio centrar-se-ão sobre $o$ processo de formação conceitual na obra vigostkyana.

A guisa de introdução consideramos importante reproduzir integralmente a firmação de Vigostky (1991, p.69), para quem

\footnotetext{
(...) num estágio inicial de seu desenvolvimento, uma criança é capaz de compreender um problema e visualizar o
} 
objetivo colocado por esse problema; como as tarefas de compreender e comunicar-se são essencialmente as mesmas para o adulto e para a criança, esta desenvolve equivalentes funcionais de conceitos numa idade extremamente precoce, mas as formas de pensamento que ela utiliza ao lidar com essas tarefas diferem profundamente das do adulto, em sua composição, estrutura e modo de operação.

Entendemos esta afirmação vigostkyana como um parágrafo especialmente esclarecedor acerca da importância da consideração, seja no âmbito da pesquisa ou no da vida cotidiana, que as crianças apresentam formas de pensamento que diferem profundamente das do adulto, ou seja, não são em si mesmas nem melhores nem piores que estas últimas. Esta "advertência" serve para que lembremos sempre de que juízos de valor sobre uma suposta "superioridade" inerente ao pensamento conceitual que se apresenta na idade adulta de um ser humano é prejudicial à compreensão global do fenômeno do pensamento humano. Com esta clara demarcação analítica e através de rigorosas experiências com crianças, o pensador russo estabeleceu a distinção clara entre patamares de desenvolvimento conceitual que se ocorrem durante $\mathrm{o}$ crescimento do indivíduo.
Para Vigotsky, o primeiro "estágio" de desenvolvimento do pensamento conceitual nos seres humanos é o agregado sincrético, o agrupamento de alguns objetos numa "agregação desorganizada, ou 'amontoado', para solucionar um problema que nós, adultos, normalmente resolveríamos com a formação de um novo conceito" (id, p. 74, grifo do autor). As palavras, neste momento inicial do desenvolvimento conceitual, denotam " $u m$ conglomerado vago e sincrético de objetos isolados" (1991, p. 74, grifo do autor). Não obstante estes objetos apresentarem-se unidos pelo frágil liame das impressões ocasionais, a coincidência pragmática entre as impressões ou relações da criança com o significado atribuído a uma palavra atribuem a esses primeiros passos no desenvolvimento conceitual infantil a capacidade de estabelecimento de uma comunicação objetiva entre a criança e os adultos com os quais interage. As palavras que se referem ao ambiente habitual da criança têm, em larga medida, o mesmo significado para estas e para seus cuidadores, o que garante o estabelecimento de uma compreensão mútua entre os mesmos.

Podemos pormenorizar a descrição deste primeiro estágio na formação do pensamento conceitual ao discriminarmos os três subestágios a seguir: 
- O subestágio da organização de grupos sincréticos através do método da tentativa e erro (1991, p.75, grifo do autor), em que a criança agrega elementos díspares e conforma uma coleção de objetos que representam uma determinada palavra de forma aleatória, baseando-se tão somente nas suposições conjunturais de determinado experimento ou situação cotidiana em que o indivíduo pode "experimentar" se a palavra que lhe é apresentada abarca ou não o conjunto de objetos que supunha designar. Podemos pensar, por exemplo, num caso em que uma criança junta elementos que estão sobre a mesa de jantar aleatoriamente: uma folha de alface, um pedaço de rabanete e outro de cenoura e diz "verdura", sendo prontamente encorajada pela mãe, que a aplaude. Em seguida, a criança coloca ao lado do grupo uma laranja, e repete a palavra "verdura", ao que sua mãe responde negativamente, dizendo-lhe que uma laranja não é uma verdura. Neste episódio poderíamos inferir que a criança talvez supusesse que a palavra "verdura" abarcaria todos os elementos que estavam disponíveis num dado conjunto e findou constatando, ainda através de um rudimentar método prático de tentativas e erros, que nem todos os objetos podem ser agrupados sobre um mesmo significado de uma palavra.
- O segundo subestágio é aquele em que a composição do grupo é em larga medida influenciada pela disposição espacial dos objetos, ou seja, "por uma organização do campo visual da criança puramente sincrética" (1991, p.75). Continuando o exemplo anterior, poderíamos expandi-lo para imaginarmos que a criança ignoraria o pedaço de cenoura que não se encontrasse disponível em seu campo visual, mas continuaria a incluir outros elementos (tais como outras frutas, por exemplo) caso estes estivessem reunidos e nele se apresentassem.

- O terceiro subestágio é designado pela progressiva estabilização e combinação dos dois outros estágios acima mencionados. A criança começa a organizar elementos a partir dos procedimentos de tentativa e erro e da discriminação de elementos isolados disponíveis em seu campo perceptual de forma mais hábil e combinada.

Este primeiro estágio fornece as bases cognitivas para que ocorra um "salto qualitativo" no desenvolvimento conceitual infantil. Do agregado aleatório de elementos isolados que se combinavam ao sabor das tentativas e da disposição espacial contígua a criança começa a agrupar elementos a partir de "relações que de fato existem entre esses objetos", delineando uma forma de pensamento que Vigotsky designou de "pensamento por 
complexos" (1991, p.76). Neste estágio a criança já não confunde suas impressões e suposições subjetivas com as relações entre as coisas, o que é um passo decisivo para a superação do sincretismo e a caminhada rumo ao refinamento do pensamento objetivo.

De forma elucidativa, Vigotsky (1991, p.76-77) esclarece que

$\mathrm{Na}$ linguagem dos adultos persistem alguns resíduos do pensamento por complexos. Os nomes da família talvez sejam o melhor exemplo disso. Qualquer nome de família, digamos 'Petrov', classifica os indivíduos de uma forma que se assemelha em muito àquela dos complexos infantis. Nesse estágio de seu desenvolvimento, a criança pensa, por assim dizer, em termos de nomes de famílias; o universo dos objetos isolados torna-se organizado para ela pelo fato de tais objetos agruparem-se em 'famílias' separadas, mutuamente relacionadas.

Estas ligações objetivas entre as "famílias" de objetos se formam através da experiência prática realizada pela criança, o que define complexo como "um agrupamento concreto de objetos unidos por ligações factuais" (1991, p.77) que carece de unidade lógica, posto que o agrupamento não se dá mediante a abstração e generalização de atributos dos elementos de um conjunto - o que caracteriza o pensamento conceitual e o que diferencia de um complexo - mas pela variedade inumerável das interações que efetivamente podem ocorrer entre estes.

Vigotsky (1991) identificou cinco tipos de complexos que se sucedem uns aos outros durante este período de desenvolvimento do indivíduo, quais sejam:

- O complexo de tipo associativo caracteriza-se por basear-se em qualquer relação percebida pela criança - de contraste ou semelhança, por exemplo entre um objeto amostral e demais objetos que o sigam. Demonstra-se aí um princípio rudimentar de conexão entre algum tipo de atributo de um objeto isolado e os demais que porventura se apresentem à criança.

-Na etapa subseqüente consiste no estabelecimento de grupos que se assemelham a coleções de objetos agrupados pelo critério da existência de atributos que os diferenciem e os tornem complementares. Uma criança que coleciona tampas de refrigerantes, por exemplo, os agrupa por características que as distinguem - suas cores ou desenhos mas que só fazem sentido juntas. Diferentemente dos "amontoados" sincréticos e dos complexos associativos, um complexo de coleções "é um agrupamento de objetos com base em sua participação na mesma operação prática em sua cooperação funcional" (1991, p. 79 , grifo do autor). 
-Segue-se então o estágio do complexo em cadeia, definido por Vigotsky (1991, p.79) como "uma junção dinâmica e consecutiva de elos isolados numa única corrente, com a transmissão de significado de um elo para o outro". A ênfase deste estágio é o deslocamento do fator aglutinador do agrupamento de objetos baseados em atributos isolados para as relações que estes mantêm entre si. Esta mudança de percepção de algo imediatamente concreto como um atributo de um determinado objeto (cor, forma etc.) para aquilo que "emerge" da interação entre os objetos, ou seja, precisamente a relação entre eles, levou o pensador russo (1991, p.79) a caracterizá-lo como "a mais pura forma de pensamento por complexos".

-O complexo difuso, por sua vez, representa o amadurecimento da qualidade "fluida" dos atributos relacionais que conformam o estágio precedente. Este tipo de pensamento expande progressivamente sua abrangência e se torna uma espécie de "guarda-chuva" cognitivo ilimitado, que "fagocita" e aglutina em torno das relações entre objetos ou características destes dadas num grupo qualquer um número cada vez maior de elementos. É importante salientar, no entanto, que "[...] esses complexos ilimitados são construídos de acordo com os mesmos princípios dos complexos concretos circunscritos” (1991, p.82) o que equivale a dizer, em outras palavras, que este tipo de pensamento não prescinde da operação prática da percepção da criança sobre o conjunto de elementos que deseja organizar.

-Por fim, a ponte entre os complexos iniciais e o estágio final da formação de conceitos é chamado de complexo de pseudoconceito, o que denota a similaridade fenotípica da generalização desta última fase do pensamento por complexos que apresenta uma criança com o pensamento conceitual em sua forma mais refinada. Importante destacar que este complexo "já carrega a semente que fará germinar um conceito" e que, devido a isso, “[...] a comunicação verbal com os adultos torna-se um poderoso fator no desenvolvimento dos conceitos infantis" (1991, p.85-86).

Antes de adentrarmos na discussão sobre o desenvolvimento do pensamento conceitual propriamente dito, próxima e decisiva etapa cognitiva infantil, nos deteremos brevemente nas implicações para nosso objeto de estudo neste ensaio, da compreensão do fenômeno do pensamento por complexos que estudamos anteriormente. Muito embora não encontremos nas obras de Vigotsky uma delimitação etária precisa para cada um dos estágios já mencionados, posto que é de acordo com as mediações socioculturais a que determinado sujeito tem acesso que 
ele poderá aceder mais ou menos precocemente a determinada aquisição conceitual, podemos supor que o pensamento por complexos é aquele que se desenvolve na criança pequena a partir dos dois anos de idade e que se estende, presumivelmente, aos onze anos, intervalo em que se encontram um grande número de crianças e adolescentes participantes da política pública de OP.

$\mathrm{O}$ autor salienta que o pensamento por complexos é o fundamento real do desenvolvimento linguiístico da espécie humana, e que o legado deste tipo de pensamento primitivo pode ser claramente visto, por exemplo, em palavras como "manga" - que pode denotar o presente do indicativo do verbo mangar (fazer galhofa, troçar), como em “ele 'manga' de alguém"; a fruta da mangueira; e, por fim, a parte de uma camisa em que há uma abertura para a passagem dos braços. Agrupar elementos heterogêneos com base em uma característica isolada dos objetos ou mediante o estabelecimento da primazia de eventuais relações concretas entre os objetos de um conjunto são, como vimos, características do pensamento por complexos em distintas fases.

Outro ponto a ser destacado é o fato de que
(...) mesmo o adulto normal, capaz de formar e utilizar conceitos, não opera com conceitos coerentemente ao pensar. À exceção dos processos primitivos dos sonhos, o adulto constantemente desvia-se do pensamento conceitual para $\mathrm{o}$ pensamento concreto semelhante aos complexos. A forma de pensamento transitória, por pseudoconceitos, não é exclusiva das crianças; nós também recorremos freqüentemente a ela em nossa vida cotidiana. (1991, p. 94, grifos nossos)

Como vimos, o pensador russo é taxativo ao afirmar a possibilidade de fluidez e de transição entre as formas de pensamento conceituais mais refinadas e aqueles ligados à concretude das relações e das percepções que caracterizam os diversos tipos de complexos. Isso implica, a nosso ver, além da possibilidade real de entendimento entre crianças e adultos, pelo menos no que concerne às características definidoras de um significante que consiga agregar elementos do cotidiano da criança, ou das quais a criança já detenha algum tipo de memória visual, conseguir compreender as diferenças entre as formas de pensamento de modo menos dicotômico e excludente.

Após a delimitação teórica do pensamento por complexos, ponto nodal importante para a compreensão do funcionamento psíquico infantil, passemos a nos debruçar de modo mais minucioso sobre o pensamento conceitual 
propriamente dito. Nesta última etapa do longo e complexo caminho de refinamento das formas de funcionamento cognitivo do ser humano observamos a importância do processo de análise-síntese e sobretudo da abstração - o isolamento e a análise de elementos abstratos separadamente da totalidade da experiência concreta da qual participam - para o entendimento da progressiva formalização das experiências cotidianas que a caracterizam.

A “jornada" rumo ao estágio mais acabado de funcionamento cognitivo, a saber, o do desenvolvimento do pensamento conceitual segue, para Vigotsky (1991), uma linha de complexificação ascendente que discriminamos a seguir:

-Primeiramente a criança, já habilitada a "colecionar" objetos num determinado grupo desde sua mais tenra idade começa, ao se aproximar da real construção conceitual, a realizar um agrupamento com grau máximo de semelhança, ou seja, há o direcionamento mais acurado da atenção para elementos dos objetos que possam ser agrupados segundo um grau de importância que lhes seja atribuído, o que denota um "início de abstração positiva e negativa" (1991, p.96). Desta forma, a criança começa a perceber que a aparência de uma cadeira "esquisita" é um elemento de menor importância na caracterização daquele objeto como uma "cadeira", posto que esta palavra engloba um conjunto de cadeiras que detêm formas variadas mas que preservam funções similares.

-A seguir vem o desenvolvimento de conceitos potenciais, que substituem os agrupamentos obtidos por máxima semelhança por aqueles relativos a um único atributo. Esta restrição torna o conceito mais rigoroso, capaz de incluir elementos heterogêneos que, no entanto, apresentem apenas um atributo que os reúna sob a égide de um significante. Interessante notar, no que diz respeito a estes conceitos, a observação de Vigotsky (1991, p.97, grifo do autor) de que neste estágio, se pedirmos a uma criança que explique uma palavra que designe um conceito abstrato, como por exemplo a palavra "sensato", ela responderá que "sensato quer dizer que estou com calor mas não me exponho a uma corrente de ar”, ou seja, ela irá traduzi-la para a linguagem funcional das ações concretas.

-Por fim, surgem os conceitos verdadeiros, o estágio final da formalização de um sentido conferido a um agrupamento de objetos designados por uma palavra, combinando o centramento ativo da atenção, a abstração de determinados traços, sua posterior síntese e, finalmente, sua simbolização por meio de um signo. 
Nas atividades de produção de desenhos em uma Assembléia do OP, por exemplo, podemos supor que a forma de pensamento conceitual surge graficamente quando, por exemplo, uma criança desenha um policial e um desenho que ela identifica como o bebedouro da escola e os coloca sob o conceito de "segurança". Para a criança ou adolescente que assim se expressa, a segurança pública simbolizada pelo desenho de um agente da lei e a segurança que ela deseja ter ao dispor de um bebedouro que não esteja vazando e deixando o chão molhado e, consequientemente, com maior risco de proporcionar a queda dos alunos na escola, o que está em jogo, poderíamos pensar, é a abstração das qualidades de ambas as situações que conformam um conceito de segurança. De igual modo a criança que consegue relacionar a ausência de esgotamento sanitário da rua em que mora e as precárias condições do posto de saúde do bairro em que vive como elementos que dizem respeito à saúde pública também, de alguma forma, a nosso ver, elaboraram um conceito de saúde que "abstrai" das características físicas ou relacionais dos elementos em questão um rol de deduções lógicas e de parâmetros de avaliação que lhes permitem abranger, sob uma mesma definição, fatos aparentemente tão mutuamente distantes quanto um pútrido córrego atulhado de fezes e lixo e um equipamento de atendimento médico.

Acreditamos que tal produção conceitual pode ser analisada sob a ótica dos estágios da formação conceitual sobre os quais discorremos acima. Como vimos na introdução deste trabalho, a atividade sobre a qual nos debruçamos estimula os participantes para que expressem sua visão de mundo através de desenhos que dão suporte à definição de conceitos diversos. Afirmamos, ademais, que a compreensão do longo e diversificado processo de formação progressiva dos conceitos em crianças e adolescentes nos permite entender a singularidade dos eventos cognitivos destes indivíduos, o que nos leva, inclusive, a ousarmos imaginar as formas através das quais podemos aceder de forma ainda mais precisa às opiniões e pontos de vista deste segmento populacional.

Por fim, como, gostaríamos ainda de lembrar, a guisa de conclusão deste ensaio, que para Vigotsky (1991; 1999; 2000) o entrecruzamento entre pensamento e linguagem promove a complexificação cognitiva dos seres humanos e dá suporte para a construção do pensamento conceitual, o estágio máximo de formalização e abstração do pensamento. Decisivo para nossos propósitos aqui é a noção de que o pensamento e a linguagem são dois processos cognitivos distintos que 
somente se entrecruzam, se reforçam e se estimulam mutuamente num determinado nível de desenvolvimento do sujeito normalmente por volta dos dois anos - e que ambos são, originariamente, formas de comportamento social - interpsicológicospara só depois serem internalizados pelo indivíduo e se transformarem em comportamentos intrapsicológicos.

Com isto queremos dizer que, para Vigotsky (1991; 1999; 2000), os seres humanos, imersos numa rede discursiva comunitária, progressivamente internalizam um sistema de comportamentos sociais, externos ao sujeito, para somente então os singularizar e analisar a partir de sua compreensão individual. Desta forma, podemos pensar que há uma "inteligência", uma "lógica", uma "imaginação" cultural, concretizadas em formas específicas de ação coletiva, que só a posteriori se tornam aquisições individuais, num movimento que vai da compreensão do "todo" do sentido do sistema de ações para suas "partes" isoladas. Avançando nesta direção poderíamos pensar também que conceitos abstratos tais como "democracia", "controle social" e "cidadania" são formas observáveis de existência das coletividades humanas que podem ser apreendidas em sua globalidade por parte das crianças e adolescentes participantes de uma comunidade na qual elas possam participar destas formas de agir. Destaca-se aí a importância da imersão dos jovens seres humanos nas atividades que queremos que eles realizem quando em sua fase adulta.

\section{Conclusão}

Nosso artigo discorreu sobre as implicações psicopedagógicas da participação de crianças e adolescentes na política pública de Orçamento Participativo de Fortaleza a partir da obra de um dos mais influentes pensadores das ciências psicológicas do século $\mathrm{XX}, \mathrm{o}$ médico e psicólogo bielo-russo L.S. Vigotsky.

Vimos também o longo e complexo processo de formação conceitual de crianças e adolescentes, desde sua mais rudimentar característica de agregação sincrética de elementos dispersos, passando pelos diversos "complexos" de pensamento até o desenvolvimento do pensamento conceitual propriamente dito. As teorias de Vigotsky a este respeito nos fornecem um amplo cabedal de indícios que nos permitem supor que os indivíduos detêm, desde sua mais tenra idade, a capacidade de formar conceitos sobre o mundo em que vivem e, consequentemente, operar sobre o meio circundante com base nestas formas de pensamento. 
A guisa de conclusão esperamos ter lançado luz sobre alguns pontos fulcrais da extensa e densa obra vigotskyana no que diz respeito aos conceitos e idéias que fornecem um embasamento para a justificação da participação de crianças e adolescentes nas atividades do OP de Fortaleza. Para o campo de saber psicopedagógico, por definição de natureza interdisciplinar, consideramos preciosa a oportunidade de abordar outros temas educacionais que não somente aqueles restritos à instituição escolar.

\section{Notas}

${ }^{1}$ A política de Orçamento Participativo de Fortaleza permite a participação de crianças e adolescentes em suas atividades entre os seis e os dezessete anos de idade incompletos. Como veremos a seguir, estes participantes realizam atividades similares aos dos participantes adultos em todas as fases do ciclo do OP, com a exceção do poder de voto no Conselho do Orçamento Participativo (COP) que, conforme alteração regimental realizada em 2010, só $\mathrm{o}$ faculta às crianças com idade superior a doze anos.

2 A Constituição Federal estabelece a obrigatoriedade da elaboração, por parte do Governo Federal, dos governos estaduais e municipais, de três leis orçamentárias que instruem o planejamento dos investimentos públicos e da gestão orçamentária dos mesmos, a saber: o Plano Plurianual PPA, realizado de quatro em quatro anos e que dispõe sobre as diretrizes gerais de dotação orçamentária das políticas públicas de um governo; a Lei de Diretrizes Orçamentárias (LDO), realizada anualmente e que especifica os percentuais específicos para cada um dos programas de governo que deverão levara cabo as indicações expressas no PPA; e a Lei Orçamentária Anual (LOA), que indica os pormenores dos empenhos orçamentários do município ou estado. É esta última lei que é composta em sua totalidade ou em parte pelas demandas apresentadas pela população nas atividades do OP.

${ }^{3}$ Dados orçamentários relativos somente ao ano de 2010 e da participação entre 2005 e 2010 de crianças e adolescentes nos ciclos territorial e escolar e adultos nos ciclos territorial e de segmentos sociais a nós repassados por meio de correio eletrônico pela Coordenação Geral do Orçamento Participativo em Janeiro de 2011 .

4 Assim são chamadas as subdivisões administrativas do município de Fortaleza. ${ }^{5}$ Este é, por exemplo, o caso do segmento "população negra". Para que uma pessoa participe de uma assembléia ou reunião comunitária com este segmento é necessário tão somente que ela se afirme como "negra", mesmo apresentando 
fenótipo que não condiga com esta afirmação.

${ }^{6}$ É preciso enfatizar que não há restrição quanto à generalidade de formulação de uma proposta, mas, antes, a orientação para que o facilitador do grupo possa torná-la mais detalhada, ou seja, com uma maior quantidade de informações que a tornem mais específica. Neste sentido, por exemplo, um grupo de crianças pode formular a proposta "queremos mais médicos". O coordenador, entretanto, deverá buscar junto aos participantes um maior esclarecimento da mesma, até obter uma proposta similar a "queremos mais dois médicos e remédios para o posto de saúde do Bairro X", considerada de qualitativamente superior à proposta inicial mais vaga.

\section{Referências}

Avritzer, L. \& Navarro, Z. (Org.). (2003). A inovação democrática no Brasil: o orçamento participativo. São Paulo: Cortez.

Avritzer, L. (2007). Sociedade civil e participação no Brasil democrático. In C. R. Melo, \& M. A. Sáez (Org.). A democracia brasileira: balanço e perspectivas para o século 21. Belo Horizonte: UFMG.
Brasil. (1990). Lei Federal 8069 de 13 de Julho de 1990. Estatuto da Criança e do Adolescente. Brasília, DF: Senado.

Ramos, G. (1984). Linhas tortas. Rio de Janeiro: Record.

Vigotsky, L. S. (2000). A formação Social da Mente. (J. C. Neto, L. S. M. Barreto \& S. C. Afeche, Trads.). São Paulo: Martins Fontes.

Vigotsky, L. S. (1991). Pensamento $e$ Linguagem. (J. L. Camargo, Trad.). São Paulo: Martins Fontes.

Vigotsky, L. S. (1999). O Desenvolvimento Psicológico na Infância. (C. Berliner, Trad.). São Paulo: Martins Fontes.

Leonardo Barros Soares é Psicólogo formado pela Universidade Federal do Ceará, especialista em Psicopedagogia pela Faculdade Christus. É militante na área da infância e adolescência e da educação para o uso crítico das mídias. Atuou durante dois anos como membro da coordenação de participação popular do gabinete da Prefeita da Prefeitura Municipal de Fortaleza.

E-mail: leonlbs@yahoo.com.br 